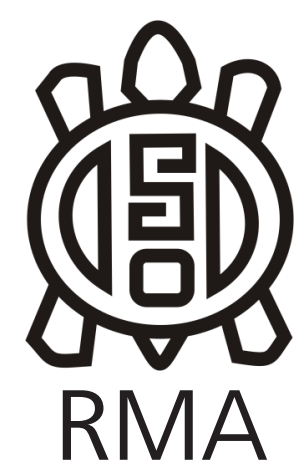

Antropología Social

\title{
Doxa y creencia entre los antropólogos
}

\author{
Doxa e crença entre os antropólogos
}

Doxa and belief among anthropologists

Traducción: María Cecilia Díaz** y Renata Oliveira Rufino***

*Programa de Pós-Graduação em Antropologia Social, Museu Nacional, Universidade Federal do Rio de Janeiro (PPGAS-MN/UFRJ)

** Instituto de Humanidades-CONICET/Universidad Nacional de Córdoba; Departamento de Antropología (FFyH, UNC) y CIFFyH, UNC. E-mail: mcecilia.diaz@ffyh.unc.edu.ar

*** Departamento de Antropología, Facultad de Filosofía y Humanidades, Universidad Nacional de Córdoba (FFyH, UNC). E-mail: renatarufino@ffyh.unc.edu.ar

*N. de T. Publicación original: Sigaud, Lygia (2007) "Doxa e crença entre os antropólogos". Novos Estudos Cebrap 77, pp. 129-152. Agradecemos especialmente a Rita Palmeira, editora de Novos Estudos Cebrap e hija de Lygia Sigaud, por su generosidad y por posibilitar la traducción del presente artículo. También agradecemos al equipo editorial de dicha revista, que autorizó la publicación, y a docentes y ayudantes alumnes de la cátedra Teoría Antropológica I (Departamento de Antropología, FFyH, UNC), por sus comentarios y sugerencias sobre una primera versión de la traducción que aquí se ofrece.

\section{Resumen}

Para explicar cómo una interpretación se vuelve hegemónica y cómo se reproducen los fenómenos de creencia colectiva, el artículo se enfoca en la recepción del Ensayo sobre el don, de Marcel Mauss, y de los diarios de Malinowski. La comparación entre los casos permite examinar los fundamentos de la legitimidad que se atribuye a ciertos intérpretes, así como también la dinámica de la estructuración y la difusión de una doxa.

Palabras clave: Doxa; Marcel Mauss; Malinowski; Antropología

\section{Resumo}

Para explicar como uma interpretação se torna hegemônica e como se reproduzem os fenômenos de crença coletiva, o artigo centra foco na recepção do Ensaio sobre o dom, de Marcel Mauss, e dos diários de Malinowski. A comparação entre os casos permite examinar os fundamentos do crédito que se atribui a certos intérpretes, bem como a dinâmica da estruturação e da difusão de uma doxa.

Palavras-chave: Doxa; Marcel Mauss; Malinowski; Antropologia.

\begin{abstract}
In order to explain how an interpretation becomes hegemonic and how collective beliefs are reproduced, the article focuses on the reception of Marcel Mauss's The Gift and of Malinowski's diaries. The comparison between the cases allows us to examine the foundations of the credibility attributed to certain interpreters, as well as the dynamics of the structuring and diffusion of a doxa.
\end{abstract}

Keywords: Doxa; Marcel Mauss; Malinowski; Anthropology. 
Al igual que en otras disciplinas, en la antropología existen interpretaciones consideradas como evidentes por sí solas, a la manera de una doxa jamás cuestionada. Las visiones dominantes respecto del Ensayo sobre el don, de Marcel Mauss (1923-24), son un ejemplo emblemático de esa especie de sentido común en la disciplina. Desde la década de 1960, antropólogos de diferentes tradiciones nacionales ven en el ensayo una teoría del intercambio cuyo principio de explicación sería la identificación entre el espíritu del donante y la cosa dada. Esa interpretación terminó por imponerse como una verdad respecto del texto de Mauss, conforme lo atestigua su consagración, por ejemplo, en la biografía escrita por Marcel Fournier (1994) y en la entrada intercambio de la Encyclopedia of social and cultural anthropology (Carrier, 1997 [1996]).

Tal interpretación contrasta fuertemente con la de los contemporáneos de Mauss, que retenía del texto sus dimensiones relativas al derecho, las obligaciones y las prestaciones totales. Así, en una reseña escrita en 1927 para la Revue historique du droit français et étranger, Henry Lévy-Bruhl describió el Ensayo sobre el don (en adelante, $E D$ ) como una contribución notable y muy útil para la historia y la prehistoria del derecho. La historia de las obligaciones, decía en ese entonces Lévy-Bruhl, podría beneficiarse del estudio de las sociedades inferiores (Fournier, 1994, p.521). El tema del derecho también llamó la atención de Bronislaw Malinowski: en una carta de 1925 escribió que había llegado a conclusiones muy semejantes a las de Mauss al trabajar sobre problemas relativos al derecho (Fournier, 1994, p.524). Sin embargo, a partir de los años sesenta, los antropólogos ya no se interesaron por los análisis de Mauss en lo que concernía al derecho y a las obligaciones. Apoyándose siempre en el mismo pasaje del texto - referente a la etnografía maorí-, pasaron a discutir la explicación mística de los intercambios en el $E D$. Ese fue un fenómeno propio del mundo de los antropólogos. En efecto, entre historiadores que se inspiraron en Mauss, como Moses Finley (1954) y Paul Veyne (1976), así como entre los estudiosos de la producción del grupo de Durkheim, como Paul Vogt

\footnotetext{
$1 \mathrm{~N}$. de T. Término griego que suele traducirse por "opinión" y que refiere al tipo de conocimiento que no ofrece certeza absoluta y no podría ser, por lo tanto, más que una creencia razonable, un conocimiento "aparente" de la realidad. Bourdieu —en quien Lygia Sigaud se inspira para estudiar las recepciones antropológicas del Ensayo sobre el Don de Mauss y el Diario de Malinowski-, recupera este término para analizar los esquemas cotidianos no reflexionados y considerados como naturales por los actores en sociedad. A lo largo de sus distintas obras, este autor despliega el concepto de doxa para contemplar formas de conocer, creencias y percepciones prereflexivas compartidas que guían la construcción de lealtad hacia las reglas del juego de los diferentes campos sociales, contribuyendo a la estabilidad de sus estructuras objetivas. Según ese enfoque, la doxa es naturalizada y difícilmente cuestionada, tanto por los científicos como por los demás actores sociales. Para un abordaje de la doxa en Bourdieu, véase Bourdieu, P. y Eagleton, T. (2003) Doxa y vida cotidiana: una entrevista. En: S. Zizek (Ed.). Ideología: un mapa de la cuestión. Buenos Aires: Fondo de Cultura Económica. p. 295308; Deer, C. (2008). Doxa. En M. Grenfell (Ed.) Pierre Bourdieu. Key Concepts. Stocksfield: Acumen.
}

(1983), no se tuvo en cuenta esa interpretación.

Evidentemente, cualquier texto es pasible de una infinidad de lecturas, y ningún autor dispone de los medios necesarios para controlar las interpretaciones que se harán de sus escritos. Las vicisitudes de Max Weber con relación a las interpretaciones corrientes de La ética protestante y el 'espíritu' del capitalismo son un ejemplo lapidario. En 1910, cinco años después de la publicación original del trabajo, el sociólogo alemán todavía estaba empeñado en replicar interpretaciones "poco inteligentes y deshonestas", pero no tenía ilusiones sobre la eficacia de sus respuestas. Weber consideraba que el público no iba a leer sus comentarios y que los críticos, como el historiador Feliz Rachfahl, tendrían siempre la última palabra: "para las personas que no conocen bien el asunto", escribía Weber (1996 [1910]), "es difícil creer que un profesor universitario de historia, tan confiado en su ignorancia, haya podido malinterpretar totalmente esta cuestión debido a una lectura completamente superficial y sesgada." (p.445).

Desde su publicación, el $E D$ fue objeto de interpretaciones diversas. Aquí no se trata de discutirlas, ni tampoco de tomar una posición en los debates que suscitaron. Mi interés incide sobre una cuestión precisa: explicar y entender cómo una interpretación, en medio de tantas otras disponibles en el mercado de ideas, se puede volver hegemónica. Para ese tipo de cuestión no se encuentran respuestas predefinidas en las intenciones de los intérpretes. Ellos tuvieron sus razones al proponer cierta interpretación, y lo que estaba en juego en esas razones debe ser considerado y comprendido. Los intérpretes tampoco tuvieron control sobre los usos de sus escritos, y si sus interpretaciones de algún modo se impusieron como dominantes en el mercado de ideas fue porque hubo quien estuviera dispuesto a atribuirles legitimidad. Se trata, por lo tanto, de examinar cómo se producen y reproducen tales fenómenos de creencia colectiva. El caso del ED será el hilo conductor y el objeto de la primera parte, la más larga de este artículo. En ella, voy a concentrarme en el texto y en su prehistoria, en el modo como fue recibido y usado por los antropólogos, en la explicación mística y en su intérprete; finalmente, procuraré mostrar cómo esa interpretación se volvió hegemónica². Con la finalidad de probar mis hipótesis a propósito de las condiciones sociales que favorecen los fenómenos de creencia colectiva, en la segunda parte, analizaré el caso de $A$ diary in the strict sense of the term, de Bronislaw Malinowski. Publicado en 1967, quince años después de la muerte de su autor, ese texto, que Raymond Firth en su introducción juzgaba ser solamente una nota al pie en la historia de la antropología (1989 [1967], p. XVIII), se volvió, a partir de los años setenta y sobre todo entre antropólogos americanos, un argumento poderoso para legitimar otra modalidad

2 Para la primera parte, retomé y reorganicé un análisis anterior sobre el ED (Sigaud, 1999) 
de hacer antropología. La comparación entre los dos casos permitirá, en la conclusión, un examen de los fundamentos de la legitimidad que se atribuye a ciertos intérpretes, como también la dinámica de estructuración y difusión de una doxa.

\section{Una obra prima}

\section{El texto en su contexto}

Marcel Mauss publicó el ED a los 46 años, cuando ocupaba la cátedra de Historia de las Religiones de los Pueblos Primitivos y No Civilizados de la École Pratique des Hautes Études en París. El texto de ciento treinta y cuatro páginas y casi quinientas notas está compuesto de una introducción, tres capítulos y una conclusión en tres partes. Los hechos etnográficos son objeto de los dos primeros capítulos. En el tercero, Mauss analiza el derecho en las civilizaciones de la Antigüedad. La conclusión se divide en conclusiones morales, conclusiones de sociología económica y de economía política, y conclusiones de sociología general y de moral.

El punto de partida del ED es la constatación de que en numerosas civilizaciones los intercambios y los contratos se hacen bajo la forma de regalos, teóricamente voluntarios, pero en realidad obligatoriamente dados y retribuidos. Según Mauss ${ }^{3}$ (1979 [1971], p.157) al comenzar el texto, el trabajo formaba parte de un conjunto de estudios más amplios de los cuales el ED sería solamente un fragmento. Hacía años que el autor se interesaba por el "régimen de derecho contractual y [por] el sistema de prestaciones económicas entre las diversas secciones o subgrupos que componen las sociedades llamadas primitivas, y también las que podríamos llamar arcaicas" (p.157). Mauss pretendía considerar sólo un rasgo de todos esos temas: "el carácter voluntario [...], aparentemente libre y gratuito, y a la vez, obligatorio e interesado de esas prestaciones". El autor aclaraba todavía que su estudio se detendría solamente en uno de los principios que habían dado ese aspecto a una forma necesaria del intercambio y que lo haría por medio de dos indagaciones: “¿Cuál es la norma del derecho y del interés que ha hecho que en las sociedades de tipo arcaico el regalo recibido haya de ser obligatoriamente devuelto? ¿Qué fuerza tiene la cosa que se da, que obliga al donatario a devolverla?" (p.157). El objetivo era doble: por un lado, llegar a conclusiones arqueológicas sobre la naturaleza de las transacciones humanas, sobre la moral y la economía de esas transacciones; por el otro, mostrar cómo esa moral y esa economía todavía funcionan en nuestras sociedades y luego deducir conclusiones de orden moral. Su método consistía en servirse de la comparación precisa,

3 N. de T.: La edición utilizada por Lygia Sigaud es la siguiente: Mauss, M. (1991) [1923-24] Essai sur le don. Forme et raison de l'échange dans les sociétés archaïques. In Sociologie et Anthropologie. Paris: PUF. Para la traducción hemos recurrido a la siguiente edición: Mauss, M. (1979 [1971]). Ensayo sobre los dones. Razón y forma del cambio en las sociedades primitivas. Sociología y Antropología. Madrid: Tecnos. En adelante, todas las citas del ED serán de esta última versión. estudiando el asunto en áreas determinadas - Polinesia, Melanesia y Noroeste americano-y algunos derechos de las civilizaciones en la Antigüedad.

Establecer relaciones entre los hechos del Noroeste americano, la Polinesia y la Melanesia y los derechos arcaicos fue producto de un largo camino recorrido por Mauss. Era notable su control de todo lo que se producía en Francia, Estados Unidos, Inglaterra y Alemania sobre el mundo primitivo, como atestiguan las setecientas reseñas que escribió para los catorce primeros volúmenes del Année Sociologique. Fue en 1910, por recomendación de Durkheim, que comenzó a interesarse por los hechos del Noroeste americano, por el potlatch descrito por Franz Boas: la destrucción ritual de las riquezas acumuladas para ofuscar al jefe rival. Al principio, creía que se trataba de una institución única en el mundo. En 1912, mientras tanto, Mauss tomó conocimiento de la etnografía sobre Melanesia realizada por Seligman y a partir de ahí identificó en otros lugares la presencia de instituciones de tipo potlatch. Por ese entonces, él ya hablaba de sistemas de prestaciones totales, en los cuales todo se intercambia. Después de la Primera Guerra Mundial, retoma el estudio de los hechos melanesios. En 1921, establece una relación entre las formas de intercambio y contrato encontradas en el Noroeste americano y en la Melanesia, y antiguos derechos indoeuropeos. En 1922, se pone a organizar las notas de Robert Hertz (su colega, muerto durante la guerra). Es en esas notas que descubre la etnografía de los maoríes realizada por Elsdon Best, la cual le permitió identificar las tres obligaciones: dar, recibir y retribuir. En 1922, Mauss encuentra la última pieza del rompecabezas en Argonauts of Western Pacific, la monografía de Bronislaw Malinowski (1922) sobre la institución del kula (intercambio de brazaletes y collares) entre los trobriandeses. Fue gracias a ese libro que pudo darse cuenta de todas las cuestiones de prestigio e interés que había en los intercambios ${ }^{4}$.

El plan del ED es inverso al camino recorrido por Mauss. El ensayo comienza por el estudio de los hechos de la Polinesia: las prestaciones totales no agonísticas. Mauss analiza el concepto de hau, el espíritu del donador que permanece en la cosa dada y que obliga a quien la recibió a retribuirla. El concepto es tratado por Mauss como una de las ideas centrales del derecho maorí. En el segundo capítulo, son analizadas las prestaciones totales agonísticas, y para eso el autor se vale de los datos relativos al kula y al potlatch. Aquí están en juego los conflictos, el lugar en la jerarquía, las ambiciones de prestigio y poder implicadas en los intercambios. En el tercer capítulo, Mauss compara las instituciones primitivas y los derechos arcaicos a fin de poner en evidencia la oposición entre sociedades como las nuestras, que distinguen los derechos sobre las cosas de los derechos

\footnotetext{
4 Para esta reconstitución del recorrido rumbo al ED me apoyé en los programas de curso de Mauss, en sus conferencias y en las notas que escribió en ese período. Ver Marcel Mauss (1969).
} 
sobre las personas, y las sociedades primitivas y las civilizaciones antiguas, en las cuales no se hace esa distinción. En sus conclusiones, Mauss consagra la primera parte a las consideraciones de orden moral. Después de subrayar la permanencia del don, de la libertad y de las obligaciones en nuestras sociedades, defiende -en lo que constituye una intervención en los debates de la época - la incorporación de la moral del don a "nuestro" derecho. En la segunda parte de la conclusión, Mauss examina las consecuencias de los hechos estudiados para el análisis de hechos económicos generales. Se trata, por un lado, de hacer estallar, así como lo hizo Malinowski, las doctrinas corrientes respecto de la economía "primitiva" e ir más allá: disolver y dar otra definición a las nociones que él mismo utilizó (como don y regalo), pues son inexactas. Por otro lado, se trata de poner en discusión conceptos de derecho y de economía frecuentemente opuestos, tales como libertad y obligación, liberalidad y generosidad, lujo y ahorro, interés y utilidad (1979, p.253). Mauss termina el ensayo con observaciones de método y estableciendo los límites de su tarea. Afirma que no proponía un modelo: el trabajo era indicativo y estaba incompleto; procuraba formular preguntas para historiadores y etnógrafos, además de sugerir objetos de investigación; no pretendía resolver un problema o proporcionar una respuesta definitiva.

El ensayo fue recibido favorablemente por antropólogos reconocidos como Malinowski en Inglaterra y Franz Boas en Estados Unidos, pero fue duramente criticado por Henri Hubert, amigo y colaborador de Mauss, quien, en una carta de 1925, señaló especialmente la falta de precisión de la noción de prestaciones sociales totales (Fournier, 1994, p.524-25). En 1926, Malinowski publicó Crime and custom, libro cuyo tema es el derecho y el orden en las sociedades primitivas. Sus cuestiones son muy cercanas a aquellas formuladas en el $E D$, es decir, se refieren a las reglas del derecho que aseguran el cumplimiento de las obligaciones. Malinowski (1970 [1926], p. 41) le dedicó a Mauss sólo una nota al pie para reconocer que su colega francés tenía razón al recordar que no existían dones gratuitos. En 1929, el ED fue objeto de una crítica de Raymond Firth en su libro sobre la economía de los maoríes. Firth, que estudiara economía en Nueva Zelanda, hizo su doctorado en Inglaterra bajo la orientación de Malinowski. Su tesis se apoyaba en la literatura disponible, ya que no había hecho trabajo de campo. La principal crítica al ED era respecto al concepto de hau, que, según Firth (1959 [1929]), no se refería al espíritu del donante, sino al espíritu de la cosa. Como su estudio era sobre los maoríes, Firth se interesó solamente por los pasajes en el ED que se ocupaban de ese pueblo de la Polinesia y sobreestimó la importancia de los datos maoríes en el texto. El autor dice, por ejemplo, que esos datos son centrales para la teoría general de la reciprocidad de Mauss (Firth, 1959, p. 421). Ahora bien, el vocablo reciprocidad ni siquiera forma parte del léxico del artículo del Année Sociologique: allí se hace referencia sólo a los dones recíprocos, lo que no se corresponde con el concepto de reciprocidad. Y el autor del ED en ninguna parte escribe que elaborará una teoría de la reciprocidad; la única teoría mencionada es la de las tres obligaciones. Mauss no le respondió a Firth. En rigor, dejó de lado el tema de los intercambios y del contrato. Su interés principal eran los rituales y las representaciones religiosas. En 1930, en el memorial que escribe Mauss para el ingreso al Collège de France, el ED era visto sólo como un momento en su recorrido (1979 [1930]).

Entre 1930 y 1940, los textos de Mauss y los que escribió con Hubert circularon y fueron leídos en Inglaterra, en los cursos de la London School of Economics (LSE), principal centro de antropología de la época, y en Estados Unidos, en las universidades de Chicago y Berkeley ${ }^{5}$. Robert Lowie, profesor en Berkeley y antropólogo de renombre, compartía el interés de los colegas de Londres por los trabajos de Mauss y Hubert. En su historia del pensamiento antropológico (1971 [1937]) son esos los únicos colaboradores de Durkheim que figuran en el capítulo sobre sociología francesa. Lowie veía el ED, para el cual ya llamara la atención, como una contribución al estudio de la jerarquía, como un ejemplo acabado de la metodología de Durkheim. Además de eso, subrayaba el carácter obligatorio del dar y del recibir, así como la idea de prestaciones totales (Lowie, 1969 [1936], p.193-6).

Los estudiosos que en la década de 1930 publicaron sobre el tema del intercambio no volvieron a Mauss. Malinowski (1935), por ejemplo, retomó la problemática de las obligaciones en su Coral Gardens sin hacer referencia al ED. El antropólogo vienés Richard Thurnwald tampoco lo cita, como señala Juillerat (1993). De hecho, la problemática no era la misma: Thurnwald se interroga sobre el origen de la reciprocidad, percibida como relaciones simétricas, mientras para el autor del $E D$ lo que importaba era identificar la regla del derecho y del interés que hace que el regalo recibido sea obligatoriamente retribuido. Además de eso, Thurnwald buscaba respuestas en mecanismos biopsíquicos, una especie de relación causal que daría escalofríos a los discípulos de Durkheim. Lo que importa destacar es que el $E D$ no era una referencia obligatoria en la época.

\section{La explicación mística y su intérprete}

En la segunda mitad de la década de 1940, el ED habría de ser destacado como el descubrimiento de la "idea fundamental de la reciprocidad" en el balance que el etnólogo Claude Lévi-Strauss hizo por ese entonces de la sociología francesa del siglo XX (Gurvitch, 1947, p.20). Al final de la década, cuando Marcel Mauss ya se encontraba enfermo y alejado de las actividades intelectuales, su ED fue invocado por el mismo autor como un trabajo "admirable", "clásico" y fuente de

5 Al respecto, véanse los programas de cursos de la LSE (The calendar of the LSE. 1937-38; 1938-39; 1947-48); Firth (1975, p.2) y Fournier (1994, p. 634-5) 
inspiración para explicar los intercambios matrimoniales por medio de lo que Lévi-Strauss denominaba principio de reciprocidad. Esa referencia está inscrita en el libro Les structures élémentaires de la parenté (1967 [1949]), originalmente la tesis de doctorado del autor, elaborada a base de la investigación en bibliotecas norteamericanas y defendida en 1948 en París ${ }^{6}$. El trabajo tenía la ambición de formular una teoría general de los sistemas de parentesco y adoptaba como método, según LéviStrauss, una especie de combinación del procedimiento de examinar ejemplos extraídos de diferentes contextos, como lo había hecho Frazer, con el de limitarse al estudio de los hechos en el propio contexto, al estilo de Durkheim. También en cuanto a esa elección metodológica, el autor reivindicaba una inspiración maussiana (1967 [1949], p. XI-XII). Lévi-Strauss abre el quinto capítulo titulado "El principio de la reciprocidad" con una referencia a las conclusiones del $E D$ :

"Mauss se propuso mostrar, en primer lugar, que en las sociedades primitivas el intercambio se presenta no tanto en forma de transacciones como de donaciones recíprocas; luego, que estas donaciones recíprocas ocupan un lugar mucho más importante en estas sociedades que en la nuestra; por fin, que esta forma primitiva de los intercambios no sólo tiene esencialmente un carácter económico, sino que nos pone en presencia de lo que con acierto denomina «un hecho social total», vale decir, dotado de una significación a la vez social y religiosa, mágica y económica, utilitaria y sentimental, jurídica y moral" (1981 [1969], p.91)

Lévi-Strauss se detiene allí y ya no vuelve al texto de Mauss. En esa parte del libro menciona sociedades en las que había intercambio por medio de dones recíprocos y apunta el ejemplo de la Polinesia, de los maoríes, refiriéndose a Best (la fuente de Hertz) y al libro de 1929 de Raymond Firth, pero no a la crítica de éste a Mauss. A lo largo del capítulo, el autor formula la tesis de que los fenómenos de intercambio se inscriben en un mismo complejo fundamental de la cultura. Más adelante, en el séptimo capítulo, desarrolla la teoría de que el origen de estos fenómenos, así como de la prohibición del incesto, de las reglas de exogamia y de las organizaciones dualistas, residiría en las "estructuras fundamentales del espíritu humano", cuya universalidad él reivindica. Tales estructuras serían la exigencia de la regla como regla; la noción de reciprocidad y el carácter sintético del don (Lévi-Strauss, 1967 [1949], p.99).

Mauss murió en 1950. Para homenajearlo, el sociólogo francés George Gurvitch organizó una compilación de textos en la que figuraba el $E D$ e invitó a Lévi-Strauss

6 N. de T. Hay una versión disponible en castellano: Lévi-Strauss, C. (1981) [1969]. Las estructuras elementales del parentesco. Paidós Básica. Buenos Aires. Para la traducción de fragmentos textuales hemos recurrido a esta versión. a escribir la introducción. Era la segunda vez que le confiaba un trabajo: el primero había sido el balance referente a la sociología francesa que se mencionó anteriormente. Los dos se conocían de Nueva York. Allí se habían refugiado durante la Segunda Guerra Mundial y actuado como profesores de la Escuela Libre de Altos Estudios. En 1950, ambos reivindicaban la herencia maussiana y estaban empeñados en rehabilitar, vía Mauss, la Escuela Sociológica francesa en el ambiente hostil al durkheimianismo de posguerra en Francia7. Durante su vida, Mauss no publicó ningún libro, y sus trabajos se encontraban dispersos en periódicos, principalmente en el Année Sociologique. La compilación, por lo tanto, se inscribía en un proyecto de editar su obra.

Lévi-Strauss inicia su "Introducción" a Sociología y Antropología (1979 [1971]) con un elogio a Mauss: dice que pocos pensadores tuvieron tamaña repercusión en Francia y se refiere a los "ecos perdurables" que su obra habría alcanzado en el exterior entre figuras como Malinowski, Radcliffe-Brown, Firth y EvansPritchard, en Inglaterra; y Redfield, Herskowits y Lloyd Warner, en los Estados Unidos (p. 13). En Francia, la influencia maussiana se había producido más por la vía del contacto regular u ocasional con colegas y discípulos y, fuera de Francia, más por medio del azar de un encuentro o una lectura que directamente por los escritos. Con esta afirmación, Lévi-Strauss instituyó el contacto personal como criterio para legitimar su pretensión en tanto intérprete autorizado: sólo los que conocieron y escucharon a Mauss —e implícitamente él se considera uno de ellos - estaban en condiciones de evaluar la fecundidad de la obra del autor y de hacer un balance. Luego inicia sus comentarios.

El pensamiento de Mauss es caracterizado como "denso" y "esotérico", "atravesado por destellos de ingeniosidad" y dado a "caminos tortuosos" que lo alejaban del recorrido que lo conduciría al "núcleo de los problemas" (p.13). Lévi-Strauss anuncia que va a destacar en la obra algunos "aspectos" y pone en evidencia el carácter precursor de los escritos de Mauss, quien desde las primeras páginas es presentado como una especie de profeta que se habría anticipado a una serie de desarrollos posteriores de la antropología. Entre el conjunto de seis textos reunidos en la primera edición de Sociologie et anthropologie, Lévi-Strauss se detiene más largamente en el ED: le dedica 16 de las 43 páginas de la "Introducción". El trabajo es presentado como un texto "capital", el "más justamente célebre", aquel cuya influencia fue más profunda, "un acontecimiento decisivo en la evolución científica", una

\footnotetext{
7 Sobre la reivindicación de la herencia maussiana, ver Karady (1968, p. IV) y Fournier (1994, p. 760-6). Es Karady quien Ilama la atención sobre el hecho de que la preocupación en rehabilitar la Escuela vía Mauss habría funcionado como criterio en la selección de los textos incluidos en la compilación. Así, sólo se escogieron textos de la "madurez" de Mauss, mientras que se dejaron de lado otros más conformes a la ortodoxia durkheimiana, probablemente para volver la enseñanza de la escuela más aceptable al gusto de la época (Karady, 1968, p. V).
} 
obra prima (p. 29). El ED jamás había recibido tantos elogios en su saga que empezara en los años veinte.

El "aspecto" del ED a explorar era la "revolución" que Mauss habría operado. Según Lévi-Strauss (1979), "por primera vez en la historia del pensamiento etnológico, se lleva a cabo un esfuerzo por superar las observaciones empíricas y llegar a realidades más profundas" (p.29). El "descubrimiento" atribuido al autor pasó entonces a ser celebrado: habría abierto nuevas posibilidades metodológicas, como aquellas exploradas por Firth con el análisis de los "ciclos de reciprocidad" entre los Tikopia; estaría cercano de los descubrimientos, también metodológicos, hechos por Troubetzkoy y Jakobson para la lingüística estructural; su relevancia sería equivalente al descubrimiento de la fonología para la lingüística; finalmente el texto habría inaugurado "una nueva era para las ciencias sociales" (p.31), y su importancia sería comparable a aquella del descubrimiento del análisis combinatorio para la matemática moderna. Aunque Mauss no hubiera explorado su propio descubrimiento, su intuición era correcta. Como prueba, Lévi-Strauss presenta otro descubrimiento más reciente en el dominio del parentesco, de "reglas concretas que permiten la creación dentro de cualquier tipo de sociedad de ciclos de reciprocidad cuyas leyes de funcionamiento son, a partir de entonces, conocidas, permitiendo así el empleo del razonamiento deductivo en un campo que parecía sujeto a la arbitrariedad más absoluta" (p.31). Lévi-Strauss no se cita a sí mismo, pero no es difícil reconocer en ese pasaje la teoría desarrollada por el autor en 1949. Así, el acierto de la reflexión de Mauss estaría en el desarrollo que él, el comentador, habría dado a su hallazgo.

Fue entonces que Lévi-Strauss ofreció una explicación para el hecho de que Mauss no hubiera explorado su propio descubrimiento, comparando al maestro con el profeta Moisés, que no logró conducir su pueblo a la Tierra Prometida. Mauss tendría la certeza lógica de que el intercambio es un denominador común de un gran número de actividades humanas. La observación empírica no le permitía ver el intercambio en los hechos, sino solamente las obligaciones de dar, recibir y retribuir. La "teoría", afirma Lévi-Strauss, exigía una estructura. No queda claro, sin embargo, de qué teoría se trata y tampoco es posible encontrar una preocupación de esa naturaleza en el ED. La solución encontrada por Mauss para el problema que le atribuye el comentador fue aplicar "una fuente de energía que opera su síntesis" (p.32). Sigue entonces una cita del ED: "se puede probar que las cosas que son objeto de cambio [...] tienen una virtud que les obliga a circular, a ser entregadas y devueltas". Lo que es suprimido de la cita, hecha sin referencia a las páginas correspondientes, permitiría al lector identificar el contexto original de la formulación. Se trata de la conclusión de la parte referente al Noroeste americano, en la cual Mauss (1979) analiza el potlatch. Aquí está la cita completa: "Profundizando más en nuestro análisis, podemos demostrar que las cosas que son objeto de cambio en el potlatch poseen una virtud que obliga a los dones a circular, a ser dados y ser devueltos". Y sigue Mauss: "Al menos los kwakiutl y los tsimshian dividen los bienes de propiedad igual que los romanos, los trobriandeños o los samoanos. Para ellos [...]" (p. 211) . Aunque no esté en juego hacer una exégesis del $E D$, no se puede concluir que allí Mauss estuviera resolviendo el problema teórico formulado por Lévi-Strauss. Él apenas presenta una concepción nativa y la relaciona con otras concepciones nativas y con las encontradas en los derechos antiguos. En la misma línea de razonamiento, el comentador escribe seguidamente que, como la virtud de la cosa no está en la cosa, sino que es concebida subjetivamente, o bien esa virtud no es sino el propio acto del intercambio, o bien es de una naturaleza diferente $y$, con relación a ella, el acto del intercambio se vuelve un fenómeno secundario. El único modo de escapar al "problema" habría sido percibir que es el intercambio el que constituye el fenómeno primitivo, y no las operaciones discretas en las cuales la vida social lo descompone. Mauss habría procurado restituir el todo con sus partes, sin embargo, como eso sería imposible, habría agregado una cantidad suplementaria. Esa cantidad sería el hau. “¿No es este quizá un caso (no tan extraño, por otra parte) en que el etnólogo se deja engañar por el indígena?" "El hau no es la razón última del cambio, sino la forma consciente bajo la cual los hombres de una sociedad determinada, en que el problema tenía una especial importancia, han comprendido una necesidad inconsciente cuya razón es otra" (p.33). Tampoco hay aquí ninguna cita del ED, ni al contexto en el cual Mauss se refirió al hau y a los juristas maoríes, tratados por Lévi-Strauss como sabios. Gracias a esa técnica argumentativa, el hau, que aparecía en Mauss como una noción central del derecho maorí, se vuelve, con Lévi-Strauss, la explicación del intercambio. Fue ese "error" que impidió que Mauss llegara a la "tierra prometida", tal como Moisés. Aquí la "tierra prometida" sería la percepción de que "la realidad subyacente al intercambio sólo puede ser encontrada en las estructuras mentales inconscientes, a las cuales se puede llegar por medio de las instituciones e incluso mejor por medio del lenguaje" (1979, p.33).

Lévi-Strauss tenía 42 años cuando publicó su "Introducción". Después de una estadía casi ininterrumpida de seis años en Nueva York, había regresado a París a fines de 1947, dispuesto a iniciar una carrera universitaria. Hasta entonces, en Francia, sólo había sido profesor de enseñanza secundaria. Sus inicios en la docencia universitaria se dieron en Brasil (1935-38), en la recién creada Universidade de São Paulo (USP). Durante la guerra, Lévi-Strauss volvió a enseñar, esta vez en Estados Unidos. Mientras estuvo allí no le faltaron invitaciones para trabajar en universidades norteamericanas prestigiosas:

8 Las negritas corresponden a las supresiones. N. de T.: A pesar de que en el texto original no encontramos ninguna sección destacada, resulta evidente que Sigaud llama la atención sobre la importancia de los fragmentos que Lévi-Strauss omite del texto de Mauss. 
rechazó todas porque ambicionaba ejercer su profesión en Francia (Cohen-Solal, 1999, p.25). Para un outsider ${ }^{9}$ autodidacta - que venía de la filosofía, no estudió etnología y, a pesar del trabajo de campo hecho en Brasil y de la publicación de algunos artículos que le valieron el reconocimiento como americanista (Peixoto, 1988, p.81-7), era visto como un antropólogo de gabinete (Héritier, 1999, p.63) - había, por lo tanto, todo un camino a recorrer para insertarse en el establishment ${ }^{10}$ científico francés. A su regreso, le pidió a Georges Davy, colaborador de Mauss y entonces titular de la cátedra de Sociología en la Sorbona, que fuera su director, para que pudiera defender la tesis que ya había presentado en Estados Unidos (Lévi-Strauss y Eribon, 1988, p.76). En 1948, fue nombrado maître de recherche en el Centre National de la Recherche Scientifique (CNRS), "un puesto de espera" (p. 80), y, luego, subdirector del Musée de I'Homme. Al año siguiente, apoyado por el historiador Lucien Febvre, a quien conoció en 1935 cuando estuvo en la USP, pasó a dictar un seminario en la École Pratique des Hautes Études (sección VI). Gracias a Georges Dumézil, otro colaborador de Mauss, fue indicado como director de estudios de la École Pratique des Hautes Etudes (sección V, de Ciencias Religiosas) y asumió la cátedra de Historia de las Religiones de los Pueblos Primitivos y No Civilizados, que Mauss ocupó entre 1901 y 1940. Por lo tanto, en poco tiempo, Lévi-Strauss logró insertarse en el mundo universitario francés con el apoyo de personas próximas a Mauss, quienes veían en él un heredero "natural" del maestro. En 1949 presentó su candidatura a la cátedra de Sociología Comparada del Collége de France y no fue aceptado. En 1950 volvió a presentarse y fue nuevamente derrotado. Las dos candidaturas, así como el sentimiento de que después de la segunda derrota su carrera estaba liquidada ${ }^{11}$, constituyen un fuerte indicio de que tenía ambiciones elevadas, de que deseaba llegar al tope de la jerarquía de prestigio, reconocimiento que le habría sido asegurado si hubiera sido elegido para el Collége de France.

En virtud del interés de insertarse en el mundo académico francés, Lévi-Strauss tenía que inscribirse en el camino abierto por Mauss, el gran nombre de la etnología en Francia. Esa era la modalidad apropiada para ser oído en aquel mundo, ser reconocido como par y obtener posiciones en las instituciones universitarias ${ }^{12}$. En los escritos de 1946 y 1949, Lévi-Strauss homenajeaba a

9 N. de T. En inglés en el original: alguien que es ajeno a un determinado grupo.

10 N. de T. En inglés en el original: conjunto de personas, instituciones y entidades influyentes en un campo determinado, que procuran mantener y controlar el orden establecido.

11 En una entrevista concedida veinte años después de ese episodio, Lévi-Strauss se refiere a este sentimiento (Clément y Grisoni, 1971, p. 24).

12 Como observa Bertholet, el hecho de ocupar un lugar en la antropología americana le confería prestigio y un peso considerable en Francia, pero no le aseguraba una posición institucional. Para ello, Lévi-Strauss necesitaba "situarse en la tradición etnológica francesa". "Por eso él añade a las referencias americanas una serie de nombres franceses. Marcel Mauss, claro." (Bertholet, 2003, p.173).
Mauss y no le hacía ninguna crítica. Aunque no compartía el punto de vista de Mauss - tanto en lo que se refiere al método (valerse de ejemplos retirados de diversas provincias etnográficas) como respecto al tratamiento dado a los intercambios (una manifestación de reglas del inconsciente, del principio de reciprocidad) - nuestro personaje hizo lo que debía hacerse al escribir su obra sobre el parentesco: se presentó como seguidor del maestro. Para avanzar en la carrera y llegar al tope debía seguir ajustándose al modo de funcionamiento del mundo académico francés: era preciso distinguirse de Mauss, ir más allá del maestro para lograr aumentar el valor de su propio "nombre", que, como señala Pierre Bourdieu (1984), es el bien más precioso del mundo académico. Con su "Introducción", Lévi-Strauss hizo nuevamente lo que debía hacerse: consagró el $E D$, dándole un valor que hasta entonces no se le había atribuido, y luego apuntó el "error" que le permitía hacer avanzar su propia teoría y, con eso, superar a Mauss. Si hubiera elegido insertarse en el mundo académico de otro país, Lévi-Strauss tal vez podría haber desarrollado su propia teoría sin necesidad de reverenciar a Mauss o de señalar sus "errores».

La comparación con el caso del antropólogo británico Edmund Leach puede ser esclarecedora en ese sentido. Como su colega francés, Leach inició su carrera en los años cuarenta. Defendió la tesis de doctorado en la London School of Economics, a los 37 años, en 1946. Al año siguiente se incorporó al equipo de la misma institución como lecturer ${ }^{13}$. En 1951 escribió un ensayo sobre parentesco con críticas devastadoras a Radcliffe-Brown, Meyer Fortes, Evans-Pritchard y LéviStrauss (Leach, 1951). Recibió por ese ensayo el Curl Prize, concedido por el Royal Anthropological Institute y atribuido por un jurado del cual participaba Meyer Fortes, uno de sus blancos, algo impensado en el mundo académico francés. Después de este episodio, Leach fue invitado a integrar la Facultad de Antropología y Arqueología de la Universidad de Cambridge por el mismo Meyer Fortes. En 1954 publicó una monografía sobre los kachin, en la cual no se apoyaba en la teoría de ningún colega y usaba su material para echar por tierra las ideas bien establecidas de los miembros del establishment de la antropología social británica (1967 [1954]). Raymond Firth, uno de los autores criticados en ese libro, escribió el prefacio, lo que sería altamente improbable en el universo francés. A lo largo de su carrera universitaria, Leach cultivó la representación de sí mismo como "herético" y fue un crítico implacable de las tesis de colegas con los cuales discordaba. Se volvió un gran "nombre" de la antropología social británica, sin necesitar rendir homenajes ni ahorrarse críticas a los colegas. Fue incluso provost ${ }^{14}$ del King's College, en la Universidad de Cambridge, con el apoyo de sus pares, y nombrado Caballero del Imperio Británico por

13 N. de T. En inglés en el original: profesor asistente.

14 N. de T. En inglés en el original: director o decano. 
la reina Elizabeth II. Si el enfrentamiento permanente no perjudicó su carrera, eso se debió a las particularidades del modo de funcionamiento del mundo académico británico. Leach no estuvo sujeto a las coerciones que se abatieron sobre Lévi-Strauss para lograr construir un "nombre" en Francia"

\section{La maorización del ED}

La crítica de Lévi-Strauss a Mauss no produjo efectos inmediatos: salvo por los comentarios de filósofos, como Claude Lefort (1967 [1951]) y Merleau-Ponty (1960), no sería exagerado decir que permaneció ignorada por algún tiempo.

En el volumen de L'Année Sociologique de 1951, Henry Lévy-Bruhl escribió el "In memoriam" a Marcel Mauss y citó la publicación de Sociologie et anthropologie, pero no la "Introducción". El ED fue entonces mencionado, entre otros textos "célebres" del autor, como un trabajo que había abierto importantes perspectivas sobre la génesis del derecho y de la economía política (LévyBruhl, 1951). En el mismo volumen fueron publicados dos artículos referidos a Mauss y al ED. Uno es de autoría de Émile Benveniste (1951), para quien el gran mérito de Mauss fue demostrar la relación funcional entre el don y el intercambio, y definir, por medio de esa relación, un conjunto de fenómenos religiosos, económicos y políticos de las sociedades arcaicas. A lo largo del texto, el lingüista procura explorar los elementos que en el vocabulario de las lenguas indoeuropeas iluminan la prehistoria de las nociones de don e intercambio (p.7-8). El segundo artículo, de Louis Gernet (1982 [1951]), está dedicado al estudio de los derechos mediterráneos de la antigüedad, notablemente de las sociedades helénicas. También allí se trata de seguir las pistas del ED y examinar representaciones religiosas y comportamientos en los cuales sea posible buscar los antecedentes de un pensamiento jurídico (p.11-2).

En 1952, en ocasión de una conferencia pronunciada en Oxford donde se encontraba como profesor visitante, el antropólogo francés Louis Dumont (1972 [1952]) resaltó la importancia de la "Introducción" para entender el impacto de la obra de Mauss en la antropología contemporánea. No se refiere, sin embargo, a los supuestos "errores" de Mauss. Dos años más tarde, Evans-Pritchard (1972 [1954]) redactó el "Prefacio" a la primera traducción inglesa del ED. La "Introducción" de Lévi-Strauss figura allí al lado del "In memoriam" de Henry Lévy-Bruhl, como ejemplo de análisis de la contribución de Mauss al pensamiento sociológico en Francia. Tampoco hay aquí ninguna palabra sobre los equívocos contenidos en el ED. Todavía en 1954, J. P. Johansen publica en Copenhague un libro sobre los maoríes. Se cita al ED como un texto que ofrece reflexiones

15 Las referencias de Leach se apoyan en un trabajo anterior, en el cual analicé su posición singular en el campo de la antropología social británica (Sigaud, 1996). finas e indiscutibles sobre el intercambio. El autor, sin embargo, hace dos advertencias: la primera, respecto de la traducción de un proverbio maorí (Johansen, 1954, p.115) y la segunda sobre el concepto de hau, que, según él, presentaría muchas más dificultades que las que Mauss percibiera (p.117-19). No hay referencias a Lévi-Strauss. Cinco años más tarde, Raymond Firth reedita su libro de 1929 sobre la economía maorí16 y no toma en cuenta la crítica de Lévi-Strauss a Mauss; en 1965 publica otro libro sobre economía primitiva y vuelve a comentar el ED: destaca la contribución de Mauss para el estudio de la naturaleza vinculante de las obligaciones en los intercambios primitivos, de la coerción social para la retribución del regalo y de la rivalidad implicada en las transacciones (Firth, 1965 [1939]). De esta manera, ni siquiera se refiere al hau y no cita la "Introducción" de 1950. Todavía en los años cincuenta, Edmund Leach (1955) escribe una reseña de la traducción del $E D$ al inglés. Como acompañaba de cerca el trabajo de Lévi-Strauss, es poco probable que desconociera la "Introducción". Sin embargo, no se refiere a ella, así como tampoco lo hace Paul Bohannan (1955, p. 60-70) en su estudio sobre el intercambio.

En los años que siguieron a la publicación de la "Introducción", Claude Lévi-Strauss no volvió a discutir el ED ni los "errores" de Mauss. Publicó trabajos importantes como Tristes trópicos (1954) y Antropología estructural (1958), se volvió una referencia en el pequeño mundo de los antropólogos, sobre todo de los especialistas en parentesco que discutían su teoría sobre la alianza, y pasó a ocupar un lugar central en la antropología francesa (Johnson, 2003, p.175). Su obra fascinaba a los filósofos, lo que ciertamente contribuyó para que también ocupara un lugar central en la escena intelectual en su país $^{17}$. En 1959 fue elegido para el Collège de France. En las dependencias de la institución creó entonces el Laboratorio de Antropología Social y fundó, en 1961, la revista $L^{\prime} H o m m e$. Tanto el laboratorio como la revista constituyeron bases sólidas para difundir su punto de vista respecto de la "buena antropología", como LéviStrauss llegó a definir su estructuralismo (Bertholet, 2003, p.325). Su fama atravesó el Atlántico: la intelectual neoyorquina Susan Sontag le dedicó un capítulo de uno de sus libros (Contra la interpretación, 1969), las revistas especializadas y los suplementos literarios presentaron artículos que reseñaban su obra, y editoriales prestigiosas publicaron libros colectivos en los cuales antropólogos, filósofos y críticos le rendían homenaje. Fue en ese nuevo contexto que su interpretación del $E D$ se volvió una referencia para los antropólogos y el interés por el trabajo de Mauss se amplió de forma notable tanto en Francia como en el mundo anglosajón, especialmente

16 N. de T. Aquí Sigaud se refiere a Economics of the New Zealand Maori (Firth, 1929)

17 Ya se ha escrito mucho sobre la preminencia de Lévi-Strauss en aquel periodo y la fascinación de los filósofos por su estructuralismo. Al respecto, ver Bourdieu y Passeron (1967), Bertholet (2003, p.179242), y Keck (2005). 
en las décadas de 1960 y 1970, momento de auge del estructuralismo.

Al final de la década de 1960, Victor Karady editaba en Francia tres volúmenes de textos de Marcel Mauss por la editorial Minuit. Del otro lado de la Mancha, Raymond Firth (1970 [1967]) ya citaba el "valioso comentario de Lévi-Strauss" respecto del trabajo de Mauss y expresaba su acuerdo con la crítica al uso de hau "como explicación del intercambio" (p.24-25). Insistía, sin embargo, retomando los argumentos de 1929, en que Mauss se había equivocado en la interpretación del hau. En 1970, Marshall Sahlins publica el artículo "The spirit of the gift: une explication de texte", en una compilación en homenaje a Lévi-Strauss. Comienza el texto con la siguiente afirmación: "el concepto central del Ensayo sobre el don es la idea nativa maorí de hau". Y agrega algunas líneas más adelante: "el hau maorí es erigido en explicación general". El autor (1970, p. 1001-2) se refiere a Lévi-Strauss como uno de los críticos de la interpretación maussiana del hau (los otros dos serían Firth y Johansen) y cita el pasaje del "error". Sahlins estuvo vinculado al Laboratorio de Antropología Social entre 1967 y 1969, y allí presentó "el resultado de su trabajo sobre la reciprocidad entre los maorí y sobre la manera por la cual Mauss y sus sucesores la habían comprendido". La relación establecida con Lévi-Strauss en aquel periodo parece haberlo marcado decisivamente: "ciertos principios del estructuralismo penetraron la vida intelectual y al menos la antropología nunca más será la misma" dijo él en una entrevista concedida en 1985 a Magazine Littéraire (Bertholet, 2003, p.325).

Todavía en 1970, escribiendo en Man, la principal revista británica de antropología, Michel Panoff (1970, p.60) destaca el ED como "un acontecimiento mayor en la historia de la teoría antropológica" y cita como evidencia la afirmación de Lévi-Strauss en la "Introducción" de 1950, de que Mauss habría sido uno de los precursores del estructuralismo. Dos años más tarde, la revista L'Arc edita un número dedicado a Mauss que contenía 13 textos. El ED aparece allí como "unánimemente considerado la obra prima del autor" y revelador del principio oculto de la reciprocidad (Dubar, 1972, p.25). La "Introducción" de Lévi-Strauss ya es reconocida como "clásica" (Condominas, 1972, p.4). Dos de los trabajos incluidos en el volumen corresponden a seminarios en los que participaron los autores, en los cuales ciertamente el ED se estaba discutiendo: es el caso del texto de Gasché (1972, p. 84) para un seminario de J. Derrida en la École Normale Superieure y del trabajo del organizador del volumen, Dennis Holler (1972, p. 61), para un curso de A. Green. En el libro que publica en 1972, Pierre Bourdieu cita la "Introducción" de Lévi-Strauss para criticar su interpretación sobre los intercambios, especialmente las leyes mecánicas que regirían el ciclo de reciprocidad, y llamar la atención sobre el intervalo entre don y contradón, y la dimensión de incerteza que rodea las transacciones -aspectos que habría de explorar posteriormente en su teoría de la práctica (1980, p. 167-89). Bourdieu (1972, p.222) menciona las críticas de Lévi-Strauss a Mauss, pero no se posiciona con relación al supuesto error del autor del ED. En 1972, L'Homme publica un largo artículo de Josselin de Jong sobre Mauss y los orígenes de la antropología estructural holandesa (p.62-84), cuyo punto de partida es la "Introducción" de 1950. En 1976, el ED sería invocado por Parkin como una de las principales referencias del concepto de intercambio. El texto entonces es asociado al principio de reciprocidad, y el autor atribuye a Mauss la percepción de un "sistema de intercambio cultural que implica mujeres, bienes, servicios y mensajes" (Parkin, 1976, p.163), en una evidente confusión entre el $E D$ y los escritos de Lévi-Strauss. Se refiere también a las críticas a Mauss hechas por Firth en 1929, que acepta sin reservas por creer que estaban amparadas en un "trabajo de campo intenso".

A partir de la década de 1980, el estructuralismo comienza a perder fuerza, pero no así la tesis de que el ED contenía una explicación mística del intercambio. Con el tiempo, la tesis se fue enriqueciendo con la recuperación de las críticas de Firth de 1929 y del artículo de Sahlins de 1970 transformado en "clásico", y se cristalizó en una especie de creencia colectiva. Todo lo que había de arbitrario y coyuntural en las interpretaciones se fue naturalizando. El texto de Mauss y el hau, los maoríes, la reciprocidad y la teoría del intercambio se volvieron entonces indisociables. Así, por ejemplo, Tambiah (1993 [1984], p.340) se refiere a la "formulación mística" del ED; Guidieri (1984, p.33) a la "noción de hau" que domina el Ensayo; Weiner (1992, p.44-65) trata el ED como el texto teórico más famoso y más controvertido sobre reciprocidad y sólo lo invoca para reanalizar datos maoríes; Godelier (1996, p.32) afirma que no puede dejar de avalar la crítica de LéviStrauss de que el hau, contrariamente a lo que pensaba Mauss, no puede ser tomado como la explicación del intercambio; Strathern (1990) escribe que Mauss había encontrado entre los maoríes "una de las ideas nativas que procuraba" (p.204); Carrier (1997 [1996])) resume así la tesis del ED en la entrada intercambio: "[en las relaciones de intercambio] el objeto dado carga la identidad del donante, que el donatario adquiere con el propio objeto" (p. 219); Fournier, el biógrafo, escribe que en su explicación del intercambio Mauss había privilegiado el "poder espiritual de las cosas" (1994, p. 520). En los últimos treinta años, el ED fue siendo "maorizado", como si se tratase apenas de la Polinesia. Se tornó reconocido como "obra prima", pero marcado indeleblemente por un error: por la mistificación del punto de vista nativo, pasó a ser visto como una teoría de la reciprocidad —noción que ni siquiera había llamado la atención de Mauss en aquel momento- y se transformó en un estudio de economía. Todo lo que había en él de referencia al derecho - tema central para Mauss y para el grupo de Durkheim - fue completamente olvidado por los antropólogos, que se enredaron en querellas sobre el hau y la explicación del 
intercambio ${ }^{18}$.

No todos los antropólogos que trataron el ED en el periodo compartían, sin embargo, la creencia colectiva sobre la explicación mística. Si observamos la antropología social británica, por ejemplo, a excepción de Firth, otras figuras expresivas no la consideraron. Edmund Leach (1996 [1970]), en el libro sobre Lévi-Strauss, ni siquiera incluye la "Introducción" en la bibliografía del autor. Para abordar lo que llama de "argumentos" del antropólogo francés sobre el intercambio, se remite al estudio de 1949 y los trata como si se inscribieran en la misma línea de pensamiento de Mauss y de los funcionalistas británicos como Firth (p. 121). Evans-Pritchard, que conoció personalmente a Mauss y tenía un gran aprecio por él, distingue el $E D$ como uno de los principales trabajos de su amigo y destaca su contribución para la comparación sistemática del intercambio de regalos y su función en la articulación del orden social. Esas observaciones son parte de la nota que escribió sobre Mauss incluida en un libro publicado póstumamente (Evans-Pritchard, 1981, p.191-2). Incluso Mary Douglas (1989), en su introducción a una traducción inglesa del $E D$, explora la dimensión interesada de los dones y ni siquiera menciona los aspectos místicos. En su trabajo sobre el don, Jonathan Parry (1986) argumenta, contra Sahlins y Lévi-Strauss, que Mauss no ofrece una explicación general a partir de una ideología específica [maorí], sino que pone en evidencia la indisociabilidad entre personas y cosas, presente también en los derechos antiguos. La importancia de ese punto del ED volvería a ser destacada por el mismo autor en una publicación posterior (Parry, 1995, p.5 y 11). Y fuera de Inglaterra habría otros ejemplos a mencionar, como Appadurai (1990 [1986]) y Ekeh (1974).

\section{El etnógrafo de los etnógrafos}

Paso ahora al análisis del caso del Diario en el sentido estricto del término (en adelante, simplemente Diario), de Malinowski, para comprobar mis hipótesis. El libro se compone de dos partes: la primera presenta notas escritas entre septiembre de 1914 y agosto de 1915, durante la estadía del autor en Mailu; la segunda contiene notas escritas entre octubre de 1917 y julio de 1918, cuando estaba en las islas trobriandesas. Allí se encuentra un repertorio de angustia, malestar en el trabajo de campo, explosiones de rabia con los nativos, pero también se ven notas acerca de método, comentarios sobre colegas, notas teóricas, observaciones sobre los nativos - que comprueban su amistad con ellos-, críticas duras a sí mismo y sobre sus relaciones con las mujeres, sus debilidades y sus deseos. Al registrar sus reacciones en un Diario, Malinowski pretendía, y dice eso repetidas

18 El artículo de Alain Testart (1998) respecto de la obligación de retribuir es un ejemplo elocuente de la amnesia de los antropólogos. En ningún pasaje del texto el autor trata esa obligación como propia del derecho primitivo. Un abordaje distinto de la teoría de la obligación en Mauss puede ser encontrado en el trabajo de un sociólogo como Vogt (1983). veces, mantener el control de sí. Fue por iniciativa de su viuda que el manuscrito polaco fue traducido al inglés y publicado en 1967. Raymond Firth escribió una introducción de ocho páginas en la que advierte a los lectores de que se trata de un "documento humano", destinado a tornarse apenas una nota al pie de página en la historia de la antropología.

La publicación del Diario fue recibida con indignación por los exalumnos de Malinowski. En la nueva introducción para la segunda edición, Raymond Firth confiesa explícitamente su incomodidad al escribir la primera y revela las reacciones que tuvieron en privado Hortense Powdermaker, Phyllis Kaberra y Lucy Mair, quienes lo reprobaron duramente por haber dado consentimiento implícito a la publicación al escribir la "Introducción": ellas temían que aquellos ya hostiles a Malinowski se sirvieran del Diario para atacarlo. En una carta dirigida a Firth en mayo de 1967, Audrey Richards le decía que Hortense Powdermaker ya detectaba cierta irritación entre los norteamericanos, especialmente con relación al empleo del término nigger para hablar de los nativos, las referencias a la rabia que Malinowski sentía por ellos y al tiempo pasado entre los europeos. En una reseña publicada en el periódico británico The Guardian, Edmund Leach, que también fuera alumno de Malinowski, condenó la publicación del Diario y enfatizó que la palabra polaca nigrami no debería haber sido traducida como nigger, error que hacía que Malinowski fuera visto como racista (Firth, 1989 [1967]).

Los recelos de Hortense Powdermaker tenían fundamento. En septiembre de 1967, la New York Review of Books, prestigiosa revista literaria norteamericana, publicó una reseña devastadora escrita por Clifford Geertz. El Diario es presentado como el golpe final contra el "mito" de Malinowski: un investigador que en su trabajo de campo tendría una empatía extraordinaria con los nativos. El método del autor de los Argonautas es cuestionado: su conducta en el campo, particularmente las explosiones de rabia, revelaba falta de empatía, y tal conducta no le hacía justicia a aquella que él mismo definía como apropiada para un investigador. Sin embargo, Geertz (1967) no aclara dónde, en su obra, Malinowski había establecido la empatía como esencia de su método.

Cuando la reseña fue publicada, Geertz tenía 41 años y ocupaba una de las cátedras del Departamento de Antropología de la Universidad de Chicago. Inició sus estudios universitarios como alumno de Letras, siguiendo después la carrera de Filosofía. En 1949, después de terminar la formación universitaria, siguió los consejos de un profesor y decidió estudiar antropología; entonces fue a cursar el doctorado en la Universidad de Harvard, donde Talcott Parsons había creado el Department of Social Relations, emprendimiento interdisciplinar que marcaría la sociología de los Estados Unidos en la década de 1950. En 1967, Geertz ya había hecho trabajo de campo en 
Indonesia (Bali y Java) y en Marruecos; había publicado artículos y libros; enseñado en Berkeley durante un año; había estado en el Center for Advanced Studies in the Behavioral Sciences en Palo Alto, donde entró en contacto con algunos grandes "nombres" de las ciencias humanas, entre ellos el sociólogo Edward Shills, el politólogo David Apter, el antropólogo británico Meyer Fortes y el lingüista Roman Jakobson. Shills y Apter lo invitaron a participar de otro proyecto interdisciplinario en la Universidad de Chicago: el Committee for Comparative Studies of New Nations, cuyo objetivo era estudiar las transformaciones sociales desencadenadas por el desmantelamiento de los imperios coloniales ${ }^{19}$.

La reseña de Geertz se inscribía en las disputas que oponían a los antropólogos de los Estados Unidos a sus colegas en Inglaterra sobre el modo de hacer antropología: privilegiar la cultura que, desde Talcott Parsons, los norteamericanos comprendían cómo el universo de los valores y símbolos, o privilegiar las relaciones sociales, como preferían los antropólogos británicos. Desde su llegada a Chicago, Geertz y David Schneider, así como otros jóvenes antropólogos, se dedicaron a modificar la enseñanza de la antropología en la universidad. La pretensión de ellos era descartar la herencia estructural-funcionalista y redefinir la antropología como el estudio de la cultura (Handler, 1991, p.607; Schneider, 1995, p.174-91). En 1963, Geertz fue invitado, junto a Marshall Sahlins, Eric Wolf y David Schneider, a presentar el punto de vista norteamericano en una reunión de la Association of Social Anthropologists (ASA), que ocurrió en la Universidad de Cambridge. En esa ocasión, criticó duramente a sus colegas europeos, a quienes consideraba parados en el tiempo, incapaces de cualquier renovación teórica. Geertz cuestionó en especial el modo como se conducían los estudios sobre religión, principalmente por relacionarse con otras dimensiones de la vida social, y expresó su punto de vista según el cual la religión debería ser estudiada como una ideología ${ }^{20}$. En la audiencia se encontraban, entre otros, Edmund Leach, Max Gluckman, Jack Goody, Audrey Richards, Raymond Firth, Meyer Fortes, todos formados directa o indirectamente por Malinowski. A pesar de los conflictos personales, todos allí se reconocían en el método de su maestro. En las notas que hizo en esa ocasión, Goody (1995, p. 146-8) registró sus reservas con relación a esa nueva manera de hacer antropología y enfatizó que, para hacer avanzar la teoría, son necesarios datos y modelos a fin de analizarlos, lo que correspondía a las lecciones de Malinowski. La publicación del Diario le dio a Geertz la oportunidad de lanzar un nuevo ataque a sus colegas del otro lado del mar al desacreditar al hombre que había inventado la antropología social británica.

19 Para los datos biográficos de Geertz usé Handler (1991), Geertz (1995) y Kuper (1999).

20 Geertz desarrolló esas ideas en el artículo "Religion as a cultural system" (1973 [1966]).
En 1970, Geertz fue invitado a ser el primer profesor de la School of Social Sciences, recién creada en la prestigiosa Universidad de Princeton, en el marco del Institute for Advanced Studies. A esa altura, él ya era un "nombre" de la antropología norteamericana y tenía triunfos importantes: había sido alumno de Talcott Parsons, algo destacable en el mundo académico norteamericano, como señala Kuper (1999), aun en un contexto de declive del modelo parsoniano; y había acumulado capital social gracias a la suerte de estar en los lugares estratégicos en el momento adecuado, como en Harvard, Palo Alto y Chicago entre las décadas de 1950 y 1960.

En 1973, Geertz publicó su manifiesto a favor de una antropología interpretativa. El propósito de la disciplina, según él, era la interpretación de los símbolos de la "cultura". Las relaciones sociales no interesaban para nada. Hacer antropología es entonces definido como hacer etnografía y ésta, a su vez, consiste una "descripción densa" (1973, p.5-6). Tal concepción representaba una ruptura, no señalada por Geertz, con el punto de vista de Malinowski, para quien la etnografía era un método, como queda claro en Baloma (1955 [1916]), Argonauts of Western Pacific (1922) y Coral Gardens (1935). En 1983, Geertz volvió a tratar sobre el Diario. El "problema" del texto, al contrario de lo que muchos habían señalado, no era de orden moral sino epistemológico. El Diario había sido para la antropología el equivalente al descubrimiento de la estructura del ADN para la biofísica, porque volvió inverosímiles las narrativas sobre el modo de trabajo de los antropólogos: "El mito del investigador de campo camaleónico, mimetizado a la perfección en sus ambientes exóticos, como un milagro andante de empatía, tacto, paciencia y cosmopolitismo, fue demolido por el hombre que tal vez más hizo por crearlo." (1983, p.56-7)21. Geertz continuaba apoyándose en dos supuestos de la reseña de 1967: que el Diario revelaba ausencia de empatía y que la empatía constituía el núcleo del método de Malinowski. El autor formula entonces la siguiente pregunta: si el conocimiento del punto de vista de los nativos no depende de la empatía, ¿cómo entonces sería posible? La solución sería el estudio de las formas simbólicas: las palabras, las imágenes, las instituciones y los comportamientos. Los comentarios sirven de preámbulo a un análisis sobre las concepciones de persona en Bali, Java y Marruecos. El modo como las presenta y las interpreta permite percibir la distancia que lo separaba del "mito". Para Malinowski, describir e interpretar creencias eran tareas complejas. Como muestra exhaustivamente en más de cien páginas de Baloma, el problema residía en cómo identificar las creencias. Para Geertz, tal cuestión ni siquiera se planteaba: él no explica al lector cómo llegó a las creencias nativas, tampoco

21 Local knowledge. Further essays in interpretive anthropology. NovaYork: Basic Books, 1983, pp. 56-7. N. de T.: para la traducción de ese fragmento recurrimos a la siguiente versión: Geertz, C. (1994). "Desde el punto de vista del nativo". Sobre la naturaleza del conocimiento antropológico.". Conocimiento local. Ensayos sobre la interpretación de las culturas. Barcelona: Paidós, p. 72. 
toma en cuenta la diversidad interna y las diferentes competencias para hablar sobre las creencias, que tanto preocupaban a Malinowski22. La diferencia no residía, por lo tanto, en la empatía, jamás invocada por éste como recomendación de método, sino en la naturaleza de las preguntas formuladas. En Geertz (1983, p. 70), la pregunta consistía en interpretar significados, tarea que propone realizar de la misma forma como se interpreta un texto o un poema.

En 1988, Geertz vuelve una vez más a la publicación de 1967, en el marco de una discusión sobre la credibilidad de los textos de los antropólogos. Defiende entonces la tesis de que la credibilidad se debe a la capacidad de "convencer" que poseen los autores, y de que el convencimiento es logrado por ellos mediante el recurso a procedimientos literarios, al hecho de haber estado "alli", en el campo. Presenta a Malinowski como el héroe que fue derrotado por su Diario, pero no le quita el mérito de haber convencido bien a sus lectores sobre el kula, y le da el epíteto de "etnógrafo de los etnógrafos" (Geertz, 1988). No se refiere a las recomendaciones metodológicas de Malinowski, como la conducta en el trabajo de campo, la recolección de datos, la elaboración de explicaciones, cuadros y diagramas, la toma de notas, la comprobación de las hipótesis, que se encuentran en los textos de carácter metodológico y en el propio Diario ${ }^{23}$. Para Geertz, las actividades del antropólogo en campo no interesan: lo que importa es el modo como narra la experiencia. El diario sirve de argumento para evidenciar la distancia entre experiencia subjetiva en el campo y los escritos académicos. Si Malinowski tuvo éxito al establecer el vínculo entre el trabajo de campo y la escritura, eso se debe a recursos literarios; si los lectores se convencen, eso no se debe a los "hechos" presentados.

Las elecciones teóricas de Geertz se relacionan con la herencia parsoniana (la cultura vista como esfera autónoma) y con la aproximación, en los Estados Unidos, entre antropología, filosofía y los estudios literarios, como muestra Kuper (1999). No se trata aquí de discutir esos escritos, sino de examinar el lugar del Diario en ellos. Malinowski fue y sigue siendo una referencia obligatoria en la disciplina. A pesar de las críticas a las supuestas "fallas" teóricas y de todo lo que se dijo sobre el Diario, es un autor ineludible siempre que se trata de enseñar a las nuevas generaciones el oficio de antropólogo; su monografía sobre el kula es considerada una etnografía

\footnotetext{
22 Mientras Malinowski consideraba que el dominio de la lengua era condición necesaria para comprender el punto de vista nativo, Geertz no se preocupaba por eso: analizó la noción de persona entre los balineses sin conocer su lengua. Cuando Handler le preguntó en la entrevista publicada en 1991 si el trabajo de campo en Bali había implicado el aprendizaje de la lengua, respondió: “No, jamás aprendí bien el balinés".

23 En un artículo sobre la importancia de los procedimientos burocráticos en las etnografías de algunos antropólogos, Kenneth Dauber (1995) analiza el caso de Malinowski y llama la atención para la preocupación con los registros precisos, valiéndose para ello también del Diario.
}

ejemplar. Aun aquellos que desean hacer una "revolución" son constreñidos a rendirle homenaje. Es el caso de Geertz, que creyó encontrar en el texto de 1967 una especie de cara oculta de la etnografía y se sirvió de eso para avanzar sus propuestas sobre el deber ser del oficio de antropólogo.

Desde la década de 1980, Geertz se tornó un personaje central en la antropología de los Estados Unidos (Kuper, 1999, p.118; 2005, p.61): fue reconocido como responsable por la renovación de la disciplina (Ortner, 1999) y como el antropólogo más influyente fuera de su círculo de pares (Sewell, 1999, p.35). Sus propuestas relativas a la antropología como interpretación de significados, a la cultura como un texto; sus discusiones sobre la escritura y la credibilidad de los textos antropológicos; su defensa de la ruptura de fronteras entre la antropología, la filosofía y la crítica literaria; y su énfasis en la preeminencia de la experiencia subjetiva del antropólogo en el campo se convirtieron en fuente de inspiración para una nueva generación de antropólogos norteamericanos como Marcus, Cushman, Fischer, Clifford, Ortner y Rosaldo ${ }^{24}$. Los debates relativos a la naturaleza de la etnografía, inaugurados por Geertz, apasionan a los jóvenes practicantes, quienes dedican largos textos a la exégesis del trabajo de campo, la escritura antropológica y al carácter experimental de la etnografía. Los procedimientos del antropólogo en campo para constituir su corpus de análisis no son objeto de debate y pasan a ser asociados al "realismo" de la antropología social británica, un paradigma que decretan superado. En ese contexto, el Diario de Malinowski es frecuentemente invocado como un documento que atestiguaría la incongruencia entre la experiencia subjetiva y las exigencias de rigor metodológico, y cuya publicación habría desencadenado una revolución en la disciplina. En las referencias al Diario, no siempre se citaba a Geertz: sus interpretaciones sobre el texto y sus veredictos respecto de las implicaciones para la etnografía ya eran, en los años ochenta, una doxa entre los antropólogos en Estados Unidos. Para los historiadores de la antropología, la etnografía y el Diario se volvieron un problema. Así, George Stocking Jr. (1983) se propuso historizar el trabajo de campo. El Diario se consideró como fuente, pero el punto de partida era la cuestión de la "empatía", del mito Malinowski, de la "desmitificación del héroe" y la experiencia en el campo, cuestiones caras a Geertz desde 1967.

En el resto del mundo anglosajón, el Diario no recibió el mismo trato. Así, en 1970, Hortense Powdermaker observa que Malinowski jamás había afirmado, ni en sus escritos ni en sus cursos, tener empatía con los nativos: eso no formaba parte de las recomendaciones precisas

24 Marcus y Cushman (1982); Marcus y Fischer (1986); Clifford y Marcus (1986); Clifford (1988); Ortner (1999); Rosaldo (1989). Un análisis detallado sobre la importancia de Geertz como fuente de inspiración para la nueva generación se encuentra en Kuper (1999, pp.201-25). 
que daba a sus alumnos que partían para el campo (1970, p. 346-47); Adam Kuper (1978 [1973]), en su historia de la antropología social británica, vuelve al Diario, pero para evidenciar el modo como Malinowski trabajaba en el campo y su "enorme creatividad"; Urry (1993), antropólogo australiano, en su historia de la antropología británica, hace referencia al texto de 1967 para señalar las recomendaciones metodológicas del autor; y, más recientemente, Michael Young (2004), su biógrafo, se sirve largamente del texto de 1967 para reconstituir la estadía de Malinowski en el campo y relacionar los datos del Diario con otras fuentes. Otros grandes nombres de la antropología norteamericana, como Marshall Sahlins, Eric Wolf y Sidney Mintz no adoptaron la nueva definición de antropología propuesta por Geertz, pero fue el punto de vista de este último el que prevaleció. La asociación que estableció entre antropología, etnografía y experiencia es, en nuestros días, la interpretación hegemónica en Estados Unidos.

\section{La doxa}

A lo largo del análisis destaqué, por un lado, a LéviStrauss, porque fue a partir de sus escritos que se produjo la inflexión en la lectura del texto de Mauss, y, por otro, a Clifford Geertz, cuyo modo de tratar el Diario se impuso como dominante. Para los dos casos fue posible formular hipótesis respecto de lo que podría estar en juego en sus interpretaciones en el contexto en que fueron formuladas: para Lévi-Strauss, en un primer momento, filiarse a Mauss para ser aceptado por sus pares en Francia y distinguirse de él por medio de la indicación del error para hacer avanzar su propia teoría y su propia carrera; para Geertz, en un primer momento demoler a Malinowski en el contexto de la disputa con los antropólogos británicos y después utilizarlo para legitimar una nueva definición del oficio de antropólogo. Una vez elaboradas, sus interpretaciones sobre el $E D$ y el Diario, como muchas otras, eran solamente nuevas mercaderías que circulaban en el mercado de las ideas. La validez atribuida a sus escritos tuvo relación con el ascenso de nuestros dos personajes en la jerarquía de prestigio dentro y fuera del mundo de los antropólogos. Fue el capital científico, esa "especie particular del capital simbólico, fundada sobre el conocimiento y el reconocimiento" (Bourdieu, 2001, p.70) que les proporcionó tanto la atención para sus escritos como la creencia en el acierto de sus interpretaciones.

En lo que respecta al ED, los primeros antropólogos que le atribuyeron legitimidad a Lévi-Strauss fueron Raymond Firth y Marshall Sahlins. No pertenecían a la misma generación, pero tenían características en común: ambos trabajaban sobre temas como la economía, los intercambios y el Pacífico Sur. Además, la argumentación de la "Introducción" se apoyaba en pasajes del $E D$ referentes a los maoríes, pueblo que los dos habían estudiado. Se comprende entonces por qué los comentarios de Lévi-Strauss llamaron su atención y por qué ellos, y no los especialistas en otras provincias etnográficas, fueron los propagadores de la interpretación de 1950. Lévi-Strauss era, desde los años cincuenta, un interlocutor privilegiado de los antropólogos en los debates sobre parentesco, que era el tema noble de la disciplina en esa época. La "Introducción" permitió que los outsiders de las disputas sobre alianza y filiación, como Firth y Sahlins, vinieran también a participar de las discusiones con la obra de quien era el faro de la disciplina. Firth y Sahlins ya tenían por ese entonces un "nombre", eran antropólogos reconocidos y profesores de dos de los principales centros de enseñanza de la disciplina: la London School of Economics y la Universidad de Chicago. El prestigio personal y el prestigio de las instituciones a las cuales estaban vinculados garantizaron que el aval dado por ambos a la interpretación de 1950 tuviera una acogida favorable.

En el caso del Diario, fueron los jóvenes antropólogos, algunos de ellos alumnos de Geertz, como Sherry Ortner, que llevaron adelante la buena nueva del maestro. Deseando participar de la "revolución" simbólica promovida por el gran "nombre" de la antropología, ellos trataron de reproducir los puntos de vista de Geertz, entre ellos el que trataba de Malinowski. En la medida en que los jóvenes también pasaron a ocupar posiciones importantes en el mundo universitario norteamericano y a hacerse un "nombre", lograron obtener una enorme audiencia para sus escritos dentro y fuera del país. El declive de la antropología social británica y el ascenso de la antropología cultural norteamericana a partir de los años setenta (Kuper, 2005) fueron ciertamente decisivos para que esos jóvenes antropólogos se impusieran en el campo de la antropología.

En los dos casos examinados, no hubo por parte de los difusores de esas interpretaciones la preocupación de recurrir ni al $E D$ ni al Diario para verificar su pertinencia. Las palabras de Lévi-Strauss y de Geertz fueron tratadas como palabras autorizadas, como si el prestigio de los dos eminentes antropólogos constituyera por sí solo una garantía del fundamento de sus afirmaciones..$^{25} \mathrm{Al}$ final, como alertaba Max Weber en el fragmento citado al inicio de este artículo, sería difícil "pensar que un profesor universitario pudiera equivocarse completamente sobre la cuestión en debate". La misma observación vale para los antropólogos que, en diferentes tradiciones nacionales,

\footnotetext{
25 El modo como Lévi-Strauss y Geertz trataron los textos de Mauss y Malinowski fue semejante. En los dos casos no hay referencia a las páginas para que el lector pueda revisar lo que se dice. Ambos intérpretes consideran que los textos en cuestión desencadenaron verdaderas revoluciones en la disciplina. Así, el ED habría abierto "una nueva era para las ciencias sociales" y su importancia para la antropología sería equivalente al descubrimiento del análisis combinatorio para la matemática moderna. Para Geertz, el Diario sería el equivalente en antropología al descubrimiento del ADN. Habría aproximaciones que se pueden hacer entre ese modo de proceder y aquel que es corriente entre profetas y magos, pero no hay espacio en este artículo para explorar esos puntos.
} 
no indagan sobre la pertinencia de las interpretaciones respecto de Mauss y Malinowski. También ellos creen en la palabra pronunciada por los "grandes nombres"; ellos creen.

La dinámica de la instauración de una doxa se sostiene por esa creencia y por el modo de funcionamiento del mundo académico. En ese mundo, los individuos desean adquirir un "nombre", ser escuchados y reconocidos como miembros plenos. La vía clásica y menos arriesgada para lograr tal objetivo es aliarse al mainstream ${ }^{26}$, seguir a los grandes "nombres". En antropología, eso se realiza sin muchos problemas: basta encuadrarse en un marco teórico y señalar la propia singularidad por el camino de la etnografía. Ese abordaje garantiza, al mismo tiempo, la escucha de los creyentes del "gran nombre" y el reconocimiento como especialista legitimado por el "trabajo de campo" (un "nombre"). Tal modo de funcionamiento contribuye para que las interpretaciones de aquellos cuyo carisma es reconocido sean evidentes por sí mismas. Pero es posible ir más allá e intentar comprender la dinámica de la doxa. La comparación con el flujo de chismes e intrigas (gossip) en Winston Parva, comunidad estudiada por Elias y Scotson (1994 [1965]), no nos alejará demasiado del asunto. Como observan los autores, la participación de los establecidos en chismes elogiosos (praise gossip) y en chismes recriminatorios (blame gossip) respecto a los outsiders les garantiza el sentimiento de pertenecer al grupo; se sienten obligados a tomar parte en el juego de intrigas porque es el costo de disfrutar de los privilegios del establishment. Uno de los elementos determinantes de la intriga es el grado de competencia para ser escuchado. Es posible avanzar en la hipótesis de que la reproducción de las interpretaciones de LéviStrauss y de Geertz formaría parte de los chismes elogiosos; la asociación del ED a "aspectos místicos" y la asociación del Diario a la destrucción del "mito" y de su método formarían parte de los chismes recriminatorios. Valorizar a unos y criticar a otros era condición necesaria para hacerse entender 0 , como sugiere Randall Collins (1988, p. 38-9), para atraer la atención y ser aceptado como miembro pleno de una comunidad; aquí, la comunidad de los antropólogos. Como en Winston Parva, aquellos que deseaban ser reconocidos como miembros estaban sometidos a coerciones; éstas, sin embargo, no eran percibidas como tales; es el observador quien las ve. En un mundo como el académico, en el cual se cree en la libertad de los individuos y en la virtud de las ideas, no sorprende que los individuos piensen la reproducción de un punto de vista simplemente como producto de la libre elección intelectual de la mejor idea en el mercado.

A lo largo de este texto, procuré indicar la existencia de antropólogos que, en el periodo estudiado, trataron el ED

26 N. de T. En inglés en el original: tendencia dominante o mayoritaria. y el Diario de otro modo, y ni siquiera tomaron en cuenta las interpretaciones de Lévi-Strauss y Geertz. Esos casos generan un nuevo conjunto de cuestiones - como la del alcance de las redes de intrigas y la de otras modalidades de constituir un "nombre" (como la herejía)—que exceden los objetivos de este trabajo. Aquí intenté simplemente tornar inteligibles los fundamentos de las creencias colectivas en una interpretación determinada, y la dinámica de una doxa. Para eso, consideré el lugar de las ambiciones personales en la producción de veredictos sobre los autores, las relaciones entre carisma y creencia y los efectos de las coerciones sufridas para ser escuchado -dimensiones frecuentemente omitidas en los análisis encantados de la repercusión de las obras. No se trató de cuestionar las obras o la importancia de las contribuciones a la teoría antropológica de Lévi-Strauss, Geertz y otros personajes aquí invocados, sino de comprender su punto de vista y su influencia. Desarrollé mi análisis con base en los casos del ED y del Diario —y podría hacerlo también a partir de diversos casos que presentan características similares - con el propósito de ofrecer pistas para el análisis de la "fuerza" de las ideas.

\section{Agradecimientos}

Una versión preliminar de este texto fue presentada en un seminario de investigación en el Centre de Sociologie Européenne, en noviembre de 2005 en París; en el coloquio Rapports ambivalents entre sciences sociales européennes et américaines, en febrero de 2006 en Liège (Bélgica), y en la clase inaugural dictada en el programa de posgrado en antropología social de la Universidade Estadual de Campinas (Unicamp), en marzo de 2006. Agradezco a los colegas presentes en los tres eventos por los comentarios y por las críticas, así como a Federico Neiburg y Miguel Palmeira por la lectura cuidadosa de esta versión ampliada.

\section{Bibliografía}

Appadurai, A. (1990) [1986] The social life of things. Commodities in cultural perspective. Cambridge/ Nova York/ Port Chester/ Melbourne/ Sydney: Cambridge University Press.

Benveniste, E. 1951. Don et échange dans le vocabulaire indo-européen. Année Sociologique. Troisième Série (1948-49).

Bertholet, D. (2003). Claude Lévi-Strauss. Paris: Plon.

Bohannan, P. (1955). "Some principles of Exchange and investment among the Tiv". American Anthropologist, 57 (1).

Bourdieu, P. (1972). Esquisse d'une théorie de la pratique. Genebra/ Paris: Librairie Droz. 
Bourdieu, P. (1980). Le Sens pratique. Paris: Éditions de Minuit.

Bourdieu, P. (1984). Homo academicus. Paris: Les Editions de Minuit.

Bourdieu, P. y Passeron, J.C. (1967). Sociology and philosophy in France since 1945: death and resurrection of a philosophy without subject. Social Research XXXIV.

Bourdieu, P. (2001). Science de la science et réflexivité. Paris: Éditions Raison d'Agir.

Carrier, J. (1997) [1996]. Exchange. In: A. Barnard \& J. Spencer. Encyclopedia of social and cultural anthropology. Londres/New York: Routledge.

Clément, C. y Grisoni, D. A. (1971). Lévi-Strauss: autoportrait. Magazine Littéraire, n.58, nov. 1971.

Clifford, J. y Marcus, G. (1986). Writing culture. The poetics and politics of ethnography. Berkeley (LA)/ Londres: University of California Press.

Clifford, J. (1988). The predicament of culture. Cambridge (Mass.) / Londres: Harvard University Press.

Condominas, G. (1972). Marcel Mauss et I'homme de terrain. L'Arc, n. 48.

Cohen-Solal, A. (1999). Claude Lévi-Strauss aux EtatsUnis: Des portes donnant accès à d'autres mondes et à tous les temps. Critique, LV.

Collins, R. (1988). The sociology of philosophies. A global theory of intellectual change. Cambridge (Mass.) / Londres: The Belknap Press of Harvard University Press.

Dauber, K. (1995) "Bureaucratizing the ethnographer's magic". Current Anthropology, 36 (1), pp. 75-95.

Douglas, M. (1989). "Il n'y a pas de don gratuit. Introduction à l'édition anglaise de I'Essai sur le don de Marcel Mauss". La Revue Mauss, n-0 4, $2^{\circ}$ semestre de 1989.

Dubar, C. (1972). Retour aux textes. L'Arc,n. 48, 1972.

Dumont, L. 1972 [1952]. Une science en devenir. L'Arc, n. 48.

Ekeh, P. (1974). Social Exchange theory. The two traditions. Londres: Heinemann Educational Books.

Elias, N. y Scotson, J. L. (1994) [1965]. The established and the outsiders. A sociological enquiry into Community problems. Londres/ Nova Delhi: Thousand Oaks/ Sage Publications.

Evans-Pritchard, E. E. (1972) [1954] Introduction à 'L'Essai sur le don', L'Arc, n. 48.

Evans-Pritchard, E. E. (1981). History of anthropological thought. Londres/ Boston: Faber and Faber.

Finley, M. (1954). The Word of Odysseus. New York: Viking Press.

Firth, R. (1959) [1929]. Economics of the New Zealand Maori. Wellington, Nueva Zelanda: R. E. Owen. Government Printer.

Firth, R. (1965) [1939] Primitive Polynesian Economy. Londres: Routledge \& Keagan Paul.

Firth, R. (1989) [1967] Introduction. In: B. Malinowski. A diary in the strict sense of the term. Stanford: Stanford University Press.

Firth, R. (1989) [1967] Second introduction. In: B. Malinowski. A diary in the strict sense of the term. Stanford: Stanford University Press.

Firth, R. (1970) [1967]. Themes in economic anthropology. A general comment. In: R. Firth (Org.). Themes in economic anthropology. Londres: Tavistock Publications.

Firth, R. (1975) "An appraisal of modern social anthropology". Annual Review of Anthropology, v.4.

Fournier, M. (1994). Marcel Mauss. Paris: Fayard, 1994.

Gasché. (1972). L'Échange héliocentrique. L'Arc, N. 48.

Geertz, C. (1967). Under the mosquito net. New York Review of Books, vol. 9, n4, set. 1967.

Geertz, C. (1973) [1967]. Religion as a cultural system. In: M. Banton (org.) Anthropological approaches to the study of religion. Londres: Tavistock Publications, pp. $1-46$.

Geertz, C. (1973). The interpretation of cultures. Basic Books.

Geertz, C. (1983). Local knowledge. Further essays in interpretive anthropology. NovaYork: Basic Books.

Geertz, C. (1988). Works and Lives. The Anthropologist as Author. Stanford: Stanford University Press. 
Geertz, C. (1995). After the fact. Two countries, four decades, one anthropologist. Cambridge (Mass.): Harvard University Press.

Gernet, L. (1982) [1951]. Droit et predroit en Grèce Ancienne. Droit et Institution en Grèce Ancienne. Paris: Flammarion.

Godelier, M. (1996). L'énigme du don. Paris: Fayard.

Goody, J. (1995). The expansive moment. Cambridge: Cambridge University Press, 1995.

Guidieri, R. (1984). L'Abondance des pauvres. Paris: Editions du Seuil.

Gurvitch, G. (1947). La sociologie française. In: Gurvitch, G. (org.). La sociologie au XX-e siècle. Paris: PUF.

Handler, R. (1991). An interview with Clifford Geertz. Current Anthropology, 32 (5)

Héritier, F. (1999). La Citadelle imprenable. Critique, T.LV., n.620-621.

Holler, D. (1972). Malaise dans la sociologie, L'Arc, N. 48.

Johansen, J. P. (1954). The Maori and his religion in its nonritualistic aspects. Copenhague: Ejnar Munksgaard.

Johnson, C. (2003). Claude Lévi-Strauss. The formative years. Cambridge, Cambridge University Press.

Josselin de Jong, P. E. (1972). Marcel Mauss et les origines de l'anthropologie structurale hollandaise. L'Homme, 12(4).

Juillerat, B. (1993). Richard Thurnwald et al Mélanesie. Réciprocités, hiérarchies, évolutions. Gradhiva: Revue d'Histoire et d'Archives de l'Anthropologie, n.14.

Karady, V. (1968). Présentation. In: Marcel Mauss. Oeuvres. 1. Les Fonctions sociales du sacré. Paris: Les Éditions de Minuit.

Keck, F. (2005). Claude Lévi-Strauss, une introduction. Paris: La Découverte.

Kuper, A. (1978) [1973]. Antropólogos e antropologia. Rio de Janeiro: Francisco Alves Editora.

Kuper, A. (1999). Culture. The anthropologists' account. Cambridge (Mass.) / Londres: Harvard University Press.

Kuper, A. (2005). Alternative histories of British social anthropology. Social Anthropology, 13 (1).

Leach, E. (1951). The structural implications of matrilineal cross-cousin marriage. Journal of the Royal Anthropological Institute, n.81.

Leach, E. (1967) [1954]. Political systems of highland Burma. Boston: Beacon Press.

Leach, E. (1955). Review of M.Mauss The Gift. Man, 55 (30).

Leach, E. (1996) [1970] Lévi-Strauss. 4a ed. Londres: Fontana Press.

Lefort, C. (1967) [1951]. A troca e a luta dos homens. In: Escobar, C. H.: O método estruturalista. Rio de Janeiro: Zahar Editores, p.64-79.

Lévi-Strauss, C. (1967) [1949]. Les structures élémentaires de la parenté. Paris: Mouton [Traducción: Lévi-Strauss, C. (1981 [1969]). Las estructuras elementales del parentesco. Paidós Básica. Buenos Aires.]

Lévi-Strauss, C. (1991) [1950] Introducción. In Mauss, M. Sociologie et anthropologie. Paris: PUF. [Traducción: Lévi-Strauss, C. (1979) [1971]. Introducción a la obra de Marcel Mauss. In Sociología y Antropología. Madrid: Tecnos]

Lévi-Strauss, C. y Eribon, D. (1988) De près et de loin. Paris: Odile Jacob.

Lévy-Bruhl, H. 1951. In memoriam. Marcel Mauss. Année Sociologique. Troisième Série (1948-49).

Merleau-Ponty, M. (1960). De Mauss à Lévi-Strauss. In Signes. Paris: Gallimard, p. 143-57.

Lowie, R. (1969) [1936]. Traité de sociologie primitive. Paris: Payot.

Lowie, R. (1971) [1937]. Histoire de l'ethnologie classique. Paris: Payot.

Malinowski, B. (1955) [1916] Baloma, The Spirits of the Dead in the Trobriand Islands. Magic, Science and Religion. Garden City, Nova York: Doubleday Anchor Books.

Malinowski, B. (1922). Argonauts of Western Pacific. Londres/ Nova York: G. Routledge \& Sons Ltd./ E.P.Dutton \& Co.

Malinowski, M. (1970) [1926]. Crime and custom in savage society. Londres: Routledge \& Kegan Paul, Ltd. 
Malinowski, B. (1935). Coral gardens and their magic. Londres: George Allen \& Unwin Ltd.

Marcus, G. y Cushman, D. (1982). Ethnographies as texts. Annual Review of Anthropology, n.11, pp. 25-69.

Marcus, G. y Fischer, M. M. J. (Orgs.). (1986). Anthropology as cultural critique. An experimental moment in the human sciences. Chicago/ Londres: The University of Chicago Press.

Mauss, M. (1979] [1930]. L'oeuvre de Marcel Mauss par lui-même, Revue Française de Sociologie, XX (1), Les durkheimiens. Etudes et documents réunis par Philippe Besnard, pp. 209-220.

Mauss, M. (1991) [1923-24] Essai sur le don. Forme et raison de l'échange dans les sociétés archaïques. Sociologie et Anthropologie. Paris: PUF. [Traducción: Mauss. M. (1979) [1971] Ensayo sobre los dones. Razón y forma del cambio en las sociedades primitivas. In Sociología y Antropología. Editorial Tecnos, Madrid.]

Mauss, M. (1969). Oeuvres 3. Cohésion sociale et divisions de la sociologie. Paris: Minuit, 1969, vol. III.

Ortner, S. (Org). (1999). The fate of 'Culture'. Geertz and beyond. Berkeley/ Londres: University of California Press.

Panoff, M. (1970). Marcel Mauss's The Gift revisited. Man, vol.5, n. 1.

Parkin, D. (1976). Exchanging words. In: Kapferer, B. (Org.). Transaction and meaning. Direction in the anthropology of Exchange and symbolic behaviour. Filadelfia: Institute for the Study of Human Issues.

Parry, J. (1986). The gift, the Indian gift and the 'Indian gift'. Man, (N. S.) 21, 1986, pp.453-73.

Parry, J. y Bloch, M. (1995 [1989]). Money and the morality of exchange. Cambridge: Cambridge University Press.

Peixoto, F. (1988). Lévi-Strauss no Brasil: A formação do etnólogo. Mana: Estudos de Antropologia Social, vol. 4, n. 1.

Powdermaker, H. (1970). Further reflections on Lesu and Malinowski's Diary. Oceania, vol.40, pp.346-7.

Rosaldo, R. (1989). Culture and truth. The remaking of social analysis. Boston: Beacon Press.
Sahlins, M. (1979). The spirit of the gift: une explication de texte. In: Pouillon, J. y Maranda, P. (Orgs.). Échanges et communications. Melanges offerts à Claude Lévi-Strauss à l'occasion de son anniversaire. Paris: Mouton.

Schneider, D. (1995). Schneider on Schneider. The Conversion of the Jews and other Anthropological Stories. Durham y Londres, Duke University Press.

Sewell Jr., W. H. (1999) Geertz, cultural history: From synchrony to transformation. In: Sherry Ortner (org.). The fate of 'Culture'. Geertz and beyond. Berkeley/ Londres: University of California Press.

Sigaud, L. (1996). Apresentação. In: Leach, E. Sistemas políticos da Alta Birmânia. São Paulo: Edusp.

Sigaud, L. (1999). As vicissitudes do 'Ensaio sobre o dom'. Mana. Estudos de Antropologia Social, 5 (2).

Sontag, S. (1994) [1966]. Contra la interpretación y otros ensayos. Barcelona, Seix Barral, pp. 154-184)

Stocking Jr., G. (1983). The ethnographer's magic. In: The ethnographer's magic and other essays in the history of social anthropology. Chicago: The University of Wisconsin Press, pp. 12-59.

Strathern, M. (1990). Negative strategies in Melanesia. In: Fardon, R. (Org.). Localizing strategies. Regional traditions of ethnographic writing. Edimburgo/ Washington: Scottish Academic Press/ Smithsonian Institution Press.

Tambiah, J. (1993) [1984]. The Budhist saints of the forest and the cult of amulets. A study in charisma, hagiography, sectarianism, and millennial Buddhism. Cambridge: Cambridge University Press.

Testart, A. (1998). Uncertainties of the 'obligation to reciprocate. In: W. James y N. J. Allen (Orgs.). Marcel Mauss. A centenary tribute. Nova York/ Oxford: Berghahn Books, p.97-110.

Veyne, P. (1976). Le Pain et le cirque. Sociologie historique d'un pluralismo politique. París: Editions du Seuil, 1976.

Vogt. P. (1983). Obligation and right: The Durkheimians and the sociology of law. In: P. Besnard (org.). The sociological domain and the founding of French school. Cambridge/Paris: Cambridge University Press/ Éditions de la Maison des Sciences de l'Homme.

Urry, J. (1993). Before social anthropology: Essays on the history of British social anthropology. Chur (Suiza): Harwood Academic Press. 
Weber, M. (1996) [1910]. Réponse finale aux critiques. In: Sociologie des religions. Paris: PUF.

Weiner, A. (1992). Inalienable possessions. The Paradox of keeping-while-giving. Berkeley: University of California
Press, 1992.

Young, M. (2004). Malinowski. Odyssey of an anthropologist: 1884-1920. New Haven/ Londres: Yale University Press. 